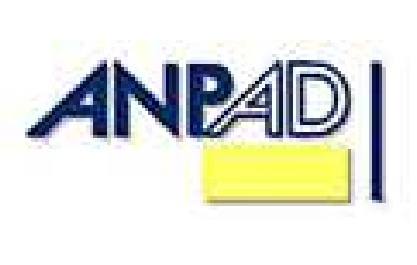

Disponível em

http://www.anpad.org.br/rac

RAC, Rio de Janeiro, v. 16, n. 4, art. 1, pp. 493-517, Jul./Ago. 2012

$(\mathrm{cc}) \mathrm{EY}-\mathrm{NC}$

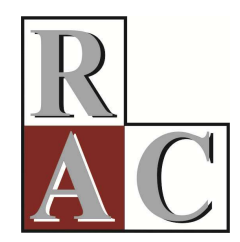

\title{
Modelagem Multicriterial Aplicada a Problemas de Regulação em Áreas Portuárias Privatizadas
}

\author{
Multi-Criteria Modeling Applied to Regulatory Issues of Privatized Port Areas
}

\author{
Ivan Ricardo Gartner * \\ E-mail: irgartner@hotmail.com \\ Universidade de Brasília - PPGA/PPGCC/UnB \\ Brasília, DF, Brasil.
}

Carlos Henrique Rocha

E-mail: chrocha@unb.br Universidade de Brasília - PPGT/UnB

Brasília, DF, Brasil.

Sérgio Ronaldo Granemann

E-mail: sergiog@unb.br Universidade de Brasília - PPGT/UnB

Brasília, DF, Brasil.

* Endereço: Ivan Ricardo Gartner

Universidade de Brasília, Departamento de Administração, Campus Darcy Ribeiro, ICC Norte, s. B1-576, Asa Norte, Brasília/DF, 70910-900.

Copyright (C) 2012 RAC. Todos os direitos, até mesmo de tradução, são reservados. É permitido citar parte de artigos sem autorização prévia, desde que seja identificada a fonte. 


\title{
Resumo
}

O objetivo deste trabalho é apresentar uma proposta de modelagem multicriterial aplicada a problemas de regulação em áreas portuárias privatizadas, tratando da hierarquização de áreas com fins de rateio de investimentos em questões de arrendamento. Os métodos multicriteriais de análise de decisão (MMAD) mostraram-se mais apropriados para a modelagem, pois o problema é de natureza multidisciplinar, envolve juízos de valor socioeconômico, ambiental e político e maior número de atores, apresenta muitos grupos de interesses com objetivos conflitantes e requer soluções de compromisso. A modelagem contou com a participação de técnicos e gerentes em regulação da Agência Nacional de Transportes Aquaviários (ANTAQ) e de pesquisadores especializados no tema. $\mathrm{Na}$ modelagem, foi considerada a conjugação do método de análise hierárquica (AHP) a procedimentos de normalização, resultando em um sistema de classificação de áreas portuárias segundo escalas de atratividade. A aplicação piloto considerou uma situação com cinco áreas hipotéticas a serem arrendadas e, ao término do processo, os técnicos em regulação podiam identificar instantaneamente a repercussão de suas escolhas na classificação final das áreas e na parcela correspondente do investimento para fins de arrendamento.

Palavras-chave: métodos multicritérios de análise de decisão (MMAD); método de análise hierárquica (AHP); arrendamento de áreas portuárias.

\begin{abstract}
The purpose of this paper is to propose a multi-criteria model applied to issues of regulation in privatized port areas with focus on prioritization of areas for purposes of investment distribution in lease issues. The multicriteria decision analysis (MCDA) method was used for modeling, since the problem is multidisciplinary, involves socioeconomic, environmental, and political judgments involves a larger number of actors, has many interest groups with conflicting goals, and requires compromise to reach a solution. The modeling was assisted by technicians and managers involved in the regulation of National Agency for Waterway Transportation (Agência Nacional de Transportes Aquaviários [ANTAQ]) as well as by researchers specializing in the topic. The model was built using a combination of the Analytic Hierarchy Process (AHP) with standardization procedures, which resulted in a rating system for port areas according to their own scales of attractiveness. The initial application considered a hypothetical situation with five areas available for lease. At the end of the process the technicians involved in regulation could instantly identify the impact choices have on area's final rankings and the corresponding portion of the investment appropriate for leasing.
\end{abstract}

Key words: multi-criteria decision analysis (MCDA); Analytic Hierarchy Process (AHP); lease of port areas. 


\section{Introdução}

O sistema portuário brasileiro tem passado por constantes adaptações para sua modernização e adequação à nova ordem econômica e competitiva mundial. Com o advento da Lei n. 8.630 (1993), o sistema passou por uma reestruturação, que culminou com a adoção de novas formas de gerenciamento da exploração dos portos e das instalações portuárias.

No conjunto de procedimentos de adequação gerencial, encontra-se a transferência da exploração da movimentação portuária para o setor privado, num sistema cujos direitos de propriedade permanecem em posse do setor público. Esse é o chamado modelo Landlord, que é adotado nos principais portos do mundo, como observam Saundry e Turnbull (1997) e World Bank (2007). A transferência dos direitos de exploração foi instituída pela Lei n. 8.630 (1993) e pelo Decreto n. 4.391 (2002), sendo que este estabeleceu os arrendamentos portuários. Tais arrendamentos são objetos de regulação e de fiscalização da Agência Nacional de Transportes Aquaviários (ANTAQ).

As resoluções editadas pela ANTAQ estabelecem que os arrendamentos portuários devem ser precedidos de estudos de avaliação dos empreendimentos aos quais se destinam. Visando a adequar seus procedimentos de avaliação às novas tendências acadêmico-científicas e de regulação econômica no âmbito internacional, a ANTAQ aliou-se ao Centro Interdisciplinar de Estudos em Transportes (CEFTRU) da Universidade de Brasília a fim de ser desenvolvida uma nova metodologia para suportar os estudos de viabilidade de projetos de arrendamento portuário, estabelecendo, inclusive, o preço mínimo do arrendamento; isto é, o preço-licitação. A partir dessa metodologia, a ANTAQ cria mais um instrumento regulatório dos portos nacionais.

Na elaboração dessa metodologia, adotou-se a abordagem proposta por Rocha, Gartner e Cavalcante (2011), segundo a qual, o valor do arrendamento referente à área portuária $k$ é dividido em duas partes: uma fixa e outra variável, da seguinte forma:

$$
C A_{k}=C A F_{k}+C A V_{k}
$$

onde $C A_{k}$ é o custo total de arrendamento da área $k, C A F_{k}$ é a parte fixa do valor do arrendamento e $C A V_{k}$ é o valor da parte variável do custo total de arrendamento da área $k$.

O valor da parte fixa do arrendamento $\left(C A F_{k}\right)$ é definido em função da avaliação imobiliária da área $k$, abrangendo os chamados espaços cobertos (como, por exemplo, prédios, silos, tanques, armazéns), e do valor do custo variável $\left(C A V_{k}\right)$. Esse valor de $C A V_{k}$ depende de $C I_{0}^{k}$, que é o valor anual da participação da área arrendada $k$ no valor presente do custo de investimento projetado do porto, e da taxa de crescimento da movimentação de cargas na área $k$ durante o período de arrendamento de acordo com a expressão:

$$
C I_{0}^{k}=\left\{\alpha_{k}\left[\sum_{t=1}^{T} \frac{C I P_{t}}{(1+\delta)^{t}}+\sum_{t=?}^{0} I A_{t}(1+\delta)^{t}\right] \times\left[\frac{(1+\delta)^{N} \delta}{(1+\delta)^{N}-1}\right]\right\} \times \theta
$$

onde $C I P_{t}$ é o custo projetado de investimento do porto no período $t, \delta$ é o custo de capital do porto, $\sum_{t=?}^{0} I A_{t}(1+\delta)^{t}$ é o valor futuro dos investimentos portuários anteriores ainda não pagos pela área $k$, sendo que $t$ pode assumir valores entre 1 e $T, \alpha_{k}$ representa a parcela dos investimentos que será absorvida pela área $k, \theta$ é um parâmetro de política, que se refere à parcela do investimento programado do porto que será coberta pelas receitas de arrendamento e $N$ é o horizonte temporal do arrendamento. Deve-se considerar que haverá tantos $\alpha_{k}$ quantas áreas houver para arrendamento no porto. 
Na equação (2), verifica-se que a variável $\alpha_{k}$ deve ser estimada a partir dos atributos portuários inerentes à área $k$, cuja definição deve levar em conta um modelo de avaliação que considere o diferencial de atratividade entre as diversas áreas portuárias a serem arrendadas. Dessa forma, o conjunto de $\alpha_{k}$ 's constituirá um vetor de pesos $\boldsymbol{\alpha}_{\mathrm{k}}$, como está ilustrado no exemplo da Tabela 1 , sendo que o conjunto de áreas arrendadas absorverá a totalidade de tais investimentos, ou $\sum_{k=1}^{n} \alpha_{k}=1$.

Tabela 1

Exemplo de Vetor de Pesos para Cinco Áreas Portuárias

\begin{tabular}{cc}
\hline Área Portuária $(k)$ & Peso $\alpha_{k}$ \\
\hline 1 & $\alpha_{1}$ \\
2 & $\alpha_{2}$ \\
3 & $\alpha_{3}$ \\
4 & $\alpha_{4}$ \\
5 & $\alpha_{5}$ \\
$\Sigma$ & $100 \%$ \\
\hline
\end{tabular}

Nota. Fonte: Elaboração dos autores.

Cabe registrar que Rocha et al. (2011) não propuseram formas de estabelecer-se o vetor de pesos $\boldsymbol{\alpha}_{\mathrm{k}}$, o que limita o alcance de sua proposta, ao mesmo tempo em que apresenta uma lacuna a ser preenchida no âmbito teórico-empírico, pois não há elementos teóricos produzidos especificamente sobre o tema, tampouco aplicações de cunho pragmático que tratem dessa problemática no âmbito das agências de regulação portuária.

Diante da existência dessa lacuna, este artigo tem como objetivo definir o vetor de pesos $\boldsymbol{\alpha}_{\mathrm{k}}$, como forma de contribuir com a hierarquização de áreas portuárias com fins de rateio de investimentos em questões de arrendamento, que é uma temática circunscrita ao âmbito da administração pública contemporânea.

O alcance desse objetivo é justificado, pois a definição das áreas para investimento portuário e a precificação de seu valor para operação pela iniciativa privada não são problemas de solução trivial, tendo em vista que parâmetros econômicos, financeiros, regulatórios, ambientais e políticos precisam ser considerados. Diante de problemas desse gênero, este estudo explora os modelos mais apropriados para seu tratamento, considerando-se que tal problemática incorpora critérios e atributos de diferentes naturezas, além de levar em consideração os pontos de vista dos diversos agentes envolvidos, ou seja, o poder público, o órgão regulador, a administração portuária e a empresa candidata à concessão.

Este artigo está estruturado em quatro partes. Na primeira parte, tem-se a introdução, que inclui a definição da problemática, do objetivo e das justificativas do trabalho. Na segunda parte, tem-se uma revisão teórica sobre modelos de decisão, que parte de um posicionamento geral até tratar de aplicações no âmbito temático explorado. A terceira parte, o desenvolvimento, descreve a metodologia proposta, que é acompanhada de uma aplicação simulada. A quarta parte apresenta as conclusões e recomendações do artigo.

\section{Modelos de Apoio à Decisão Aplicados à Avaliação de Projetos Portuários}

A definição do vetor de pesos $\boldsymbol{\alpha}_{\mathrm{k}}$ pode ser feita utilizando-se procedimentos metodológicos e processos de modelagem distintos, cujos resultados finais podem ser divergentes. Logo, o 
desenvolvimento de uma metodologia para atender a esse propósito reveste-se, por si só, de uma problemática a ser superada em função de considerações técnicas e científicas que justifiquem a opção por um processo de modelagem único ou pela combinação de dois ou mais modelos.

Entre os grupos de modelos aplicados em problemáticas de construção de vetores de pesos para problemas de avaliação e de tomada de decisão, há contribuições especiais no âmbito da pesquisa operacional, sobretudo em suas áreas de programação matemática e de modelos multicritérios de análise de decisão (MMAD). Uma diferença bastante aceita, entre essas duas áreas de modelagem, diz respeito ao caráter objetivo ou subjetivo da abordagem do problema; sendo que os modelos de programação matemática são mais inerentes ao caráter objetivo e os modelos multicritérios de análise de decisão (MMAD) estão mais associados ao caráter subjetivo.

Enquanto que os modelos de programação matemática utilizam eminentemente informações quantitativas e de maior homogeneidade dimensional, sendo que suas orientações decisórias trabalham com operadores ótimos de maximização ou minimização (ou ambos, no caso de modelos multiobjetivos); os MMAD destinam-se à agregação de informações quantitativas e qualitativas, que são direcionadas à busca por soluções não ótimas, mas que sejam satisfatórias por satisfazerem às preferências e valores dos decisores. Nesse aspecto, verifica-se que a natureza do problema decisório dirige o tipo de metodologia a ser utilizada. Por exemplo, problemas de análise de investimentos corporativos nos âmbitos tático e operacional costumam ser conduzidos por modelos de programação matemática, visto que as variáveis envolvidas concentram elementos de produtividade e desempenho (ambos de natureza objetiva). Já os problemas de análise de investimentos corporativos no âmbito estratégico são mais complexos, pois além de incluírem variáveis quantitativas de produtividade e desempenho, envolvem variáveis qualitativas de caráter político (de natureza subjetiva), o que pode levar a corporação a definir metas satisfatórias, ao invés de ótimas.

Os MMAD podem tratar dessa subjetividade inerente às variáveis qualitativas, pois permitem que os tomadores de decisão expressem, de forma explícita, suas preferências e valores, ao mesmo tempo em que têm de estar unidos em função do alcance de um objetivo comum, mesmo que isso os faça afastar-se em algum grau de seus próprios anseios.

Por essas razões, a aplicação de modelagem multicriterial é encontrada com frequência no suporte a processos decisórios corporativos e do setor público. Em relação ao setor público, encontram-se referências a aplicações dos MMAD a processos decisórios estratégicos em Grizzle (1987), Keeney (1988) e Saaty (1995). Em Saaty (2008), pode-se encontrar uma lista ampla de aplicações dos MMAD na administração pública, notadamente do método AHP.

No Brasil, a literatura científica sobre aplicações dos MMAD em problemas da administração pública é limitada. Como exemplo, pode-se citar o trabalho recente de Menezes, Silva e Linhares (2007), no qual é proposta uma abordagem de decisão multicriterial como alternativa à adoção de leilões reversos baseados em atributos múltiplos para maior agregação de valor pelas organizações compradoras do setor público brasileiro. Ao se considerar a busca específica a trabalhos científicos que tratem da aplicação dos MMAD, nas questões de regulação e gestão portuária no Brasil, não são encontradas referências publicadas, o que demonstra que há uma lacuna no meio acadêmico nacional sobre o tema.

No âmbito internacional, encontram-se aplicações dos MMAD a problemas de planejamento e gestão das atividades portuárias, mas, em número reduzido. Além disso, as poucas aplicações encontradas consideraram o método de análise hierárquica (AHP) como principal ferramental utilizado. Nesse aspecto, podem ser citados os estudos de:

Satir, Alkan, Cane e Bak (2007), que apresentam a aplicação do AHP para a seleção da área mais apropriada do porto para atracagem com o objetivo de reduzir e eliminar a poluição gerada pelos navios.

Chou (2010), que aplicou o AHP para modelar a seleção de um porto em uma região de muitos portos, com o objetivo de redução dos custos de transporte. 
Harahap, Santoso e Suryadi (2005), que tratam da aplicação do AHP como objetivo de selecionar o melhor modelo de privatização para a gestão de terminais portuários marítimos no porto de Tanjung Priok.

Embora tais estudos apresentem aplicações do AHP à problemática do planejamento portuário, nenhum deles apresenta convergência considerável com o objeto deste estudo, que trata da diferenciação de atratividade das áreas portuárias com fins de arrendamento. Logo, este trabalho dispõe-se a contribuir com a construção do conhecimento neste campo específico.

\section{Metodologia de Modelagem para Hierarquização de Áreas Portuárias}

\section{Fundamentação metodológica}

O problema da diferenciação de atratividade das áreas portuárias é de complexidade exacerbada, pois, como toda problemática no âmbito da regulação do setor público, apresenta natureza multidisciplinar (Avouris, 1995) e envolve julgamentos de valor socioeconômico, ambiental e político (Munda, Nijkamp, \& Rietveld, 1995), que são de complexa ou pouco provável mensuração econômica, muitas vezes, sendo expressos somente na forma qualitativa, o que envolve maior número de atores, cujas responsabilidades não são claras (Gray et al., 1996); apresenta muitos grupos de interesses com objetivos conflitantes (Button \& Nijkamp, 1997) e requer soluções de compromisso (Funtowicz, Munda, \& Paruccini, 1990).

Os MMAD possibilitam tratar dessa complexidade, além de cumprir com outros requisitos técnicos de processos de avaliação no âmbito público, como diferenciação entre a magnitude e importância do impacto, explicitação dos critérios para a determinação da importância, abordagem qualitativa da importância, utilização da opinião pública e de outras formas de consulta e possibilidade de agregação dos impactos.

Uma importante característica dos MMAD é relativa aos seus procedimentos metodológicos de aplicação. Sua aplicação é feita em duas fases distintas, mas intrinsecamente unidas, que são a estruturação e a avaliação (Bana e Costa \& Vincke, 1990), sendo que, ao final do processo, são propostas as recomendações aos decisores, o que caracteriza os MMAD como instrumentos de apoio ao processo decisório.

O processo de aplicação dos MMAD começa com a estruturação da situação decisória, que usualmente se enquadra em um dos quatro tipos de problemas citados por Roy (1985):

- Problemática do tipo $\alpha$, de escolha: é a seleção de somente uma das alternativas.

- Problemática do tipo $\beta$ de triagem: é a escolha de todas as boas alternativas.

. Problemática do tipo $\gamma$ de classificação: é a escolha de algumas das melhores alternativas.

- Problemática do tipo $\delta$, de descrição: é a descrição das alternativas e suas consequências.

O tipo de problema a ser avaliado conduz à forma de estruturação, que inclui a determinação e avaliação dos envolvidos, a emergência da decisão, as alternativas, as consequências, os aspectos importantes (critérios) e a quantidade e qualidade das informações.

Em síntese, na estruturação de um problema de múltiplos critérios, tem-se o levantamento do conjunto de alternativas A e do conjunto de critérios F conforme a seguinte notação:

$A=\left\{a_{1}, \ldots, a_{i}, \ldots, a_{n}\right\}$, conjunto de alternativas; 
. $F=\left\{g_{1}, \ldots, g_{j}, \ldots, g_{m}\right\}$, conjunto de critérios de avaliação.

Assim, as alternativas do conjunto $A$ serão confrontadas entre si por seus desempenhos nos critérios do conjunto $F$, cuja valoração de cada alternativa em cada critério tem a notação $\mathrm{g}_{\mathrm{j}}\left(\mathrm{a}_{\mathrm{i}}\right)$, e os resultados são tabulados em uma matriz de avaliação do tipo:

\begin{tabular}{c|ccccc}
\hline & $g_{1}$ & $\cdots$ & $g_{j}$ & $\cdots$ & $g_{m}$ \\
\hline$a_{1}$ & $g_{1}\left(a_{1}\right)$ & $\cdots$ & $g_{j}\left(a_{1}\right)$ & $\cdots$ & $g_{m}\left(a_{1}\right)$ \\
$\vdots$ & $\vdots$ & $\ddots$ & $\vdots$ & $\ddots$ & $\vdots$ \\
$a_{i}$ & $g_{1}\left(a_{i}\right)$ & $\cdots$ & $g_{j}\left(a_{i}\right)$ & $\cdots$ & $g_{m}\left(a_{i}\right)$ \\
$\vdots$ & $\vdots$ & $\ddots$ & $\vdots$ & $\ddots$ & $\vdots$ \\
$a_{n}$ & $g_{1}\left(a_{n}\right)$ & $\cdots$ & $g_{j}\left(a_{n}\right)$ & $\cdots$ & $g_{m}\left(a_{n}\right)$ \\
\hline
\end{tabular}

A valoração das alternativas ocorre na avaliação do problema, durante as fases de articulação e modelagem e de agregação das preferências. A articulação e modelagem das preferências são oriundas dos julgamentos dos decisores que, num sentido amplo, são extraídos das situações fundamentais resultantes da comparação paritária entre as alternativas (vide Tabela 2).

Tabela 2

Situações Fundamentais Resultantes da Comparação de Duas Alternativas

\begin{tabular}{llc}
\hline \multicolumn{1}{c}{ Situação } & \multicolumn{1}{c}{ Definição } & Relação binária \\
\hline Indiferença & $\begin{array}{l}\text { As duas ações potenciais são indiferentes no sentido de existir } \\
\text { razões claras e positivas de escolher a equivalência. }\end{array}$ & $\begin{array}{c}\boldsymbol{I} \text { : simétrica } \\
\text { reflexiva }\end{array}$ \\
\hline Preferência estrita & $\begin{array}{l}\text { Existem razões claras e positivas para justificar que uma (bem } \\
\text { especificada) de duas ações é significantemente preferida à outra. }\end{array}$ & $\begin{array}{c}\boldsymbol{P} \text { : assimétrica } \\
\text { irreflexiva }\end{array}$ \\
\hline Preferência fraca & $\begin{array}{l}\text { Uma (bem especificada) de duas ações não é estritamente preferida à } \\
\text { outra, mas é impossível dizer se a outra é estritamente preferível ou } \\
\text { indiferente à primeira, porque nenhuma das duas situações anteriores } \\
(\boldsymbol{I} \text { ou } \boldsymbol{P}) \text { predomina. }\end{array}$ & $\begin{array}{c}\boldsymbol{Q} \text { : assimétrica } \\
\text { irreflexiva }\end{array}$ \\
\hline Incomparabilidade & $\begin{array}{l}\text { As duas ações não são comparáveis no sentido de que nenhuma das } \\
\text { três situações anteriores }(\boldsymbol{I}, \boldsymbol{P} \text { ou } \boldsymbol{Q}) \text { predomina. }\end{array}$ & $\begin{array}{c}\boldsymbol{R} \text { : simétrica } \\
\text { irreflexiva }\end{array}$ \\
\hline
\end{tabular}

Nota. Fonte: Adaptado de Roy, B., \& Vincke, P. (1984). Relational systems of preference with one or more pseudo-criteria: some new concepts and results (p. 1327). Management Science, 30(11), 1323-1335. doi: 10.1287/mnsc.30.11.1323

Após terem sido obtidas as preferências do decisor, parte-se para sua agregação, que define o tipo do método MMAD a ser aplicado. Baseando-se no procedimento de agregação das preferências, autores, como Roy (1985) e Bana e Costa e Vincke (1990), classificam os MMAD principalmente em dois grupos de métodos: (a) métodos de critério único de síntese e (b) métodos Outranking.

Os métodos de critério único de síntese, usualmente associados à escola americana, assumem que existe uma função de utilidade ou função de valor para representar as preferências dos decisores. Assim, a tarefa do analista consiste da avaliação de tal função e, em consequência, a classificação das alternativas é direta (direct rating). A avaliação desta função pode ser obtida pelo emprego de modelos aditivos, multiplicativos, entre outros, com a hipótese de que existe uma função parcial de utilidade $u_{j}$ de acordo com cada atributo $j$. Esses métodos de critério único de síntese adotam o princípio da transitividade, isto é, se A é preferível a B e B é preferível a C, então, A é preferível a C. Tomando-se como base esse princípio, alguns desses métodos possuem testes de consistência dos julgamentos. 
Esses métodos não admitem a incomparabilidade das alternativas, geralmente, considerando somente as situações de preferência e indiferença, o que resulta em ordenamentos totais das alternativas.

Os métodos outranking, também conhecidos como Métodos Multicritérios de Apoio à Decisão (MCDA), fazem parte da ala europeia de estudos de métodos multicritérios, seus principais pesquisadores são franceses e belgas. Deve ser destacada a participação do pesquisador francês Bernard Roy, que estabeleceu as bases científicas desse grupo de métodos. Roy (1990) define uma relação outranking como sendo binária e que compara os argumentos prós e contras à hipótese de que a alternativa $a$ é ao menos tão boa quanto a alternativa $b$. Isso é o mesmo que dizer que $a$ é "não pior que" $b$, com a seguinte notação: $a \boldsymbol{S} b$ (a outrankings $b$ ). Uma relação outranking $(\boldsymbol{S}$ ) permite o tratamento da incomparabilidade entre as ações, o que de fato pode ocorrer em casos práticos, principalmente pela incerteza e imprecisão dos dados utilizados e pelas características próprias do decisor. Além disso, uma relação outranking não precisa atender ao princípio da transitividade. Esta abordagem define condicionantes num sistema de preferências, no qual devem ser enquadrados os desempenhos fornecidos pelo decisor para cada uma das ações.

Em termos comparativos, a principal diferença entre os dois grupos de modelos está associada ao fluxo de processamento e aos resultados apresentados, como pode ser visto na Figura 1.

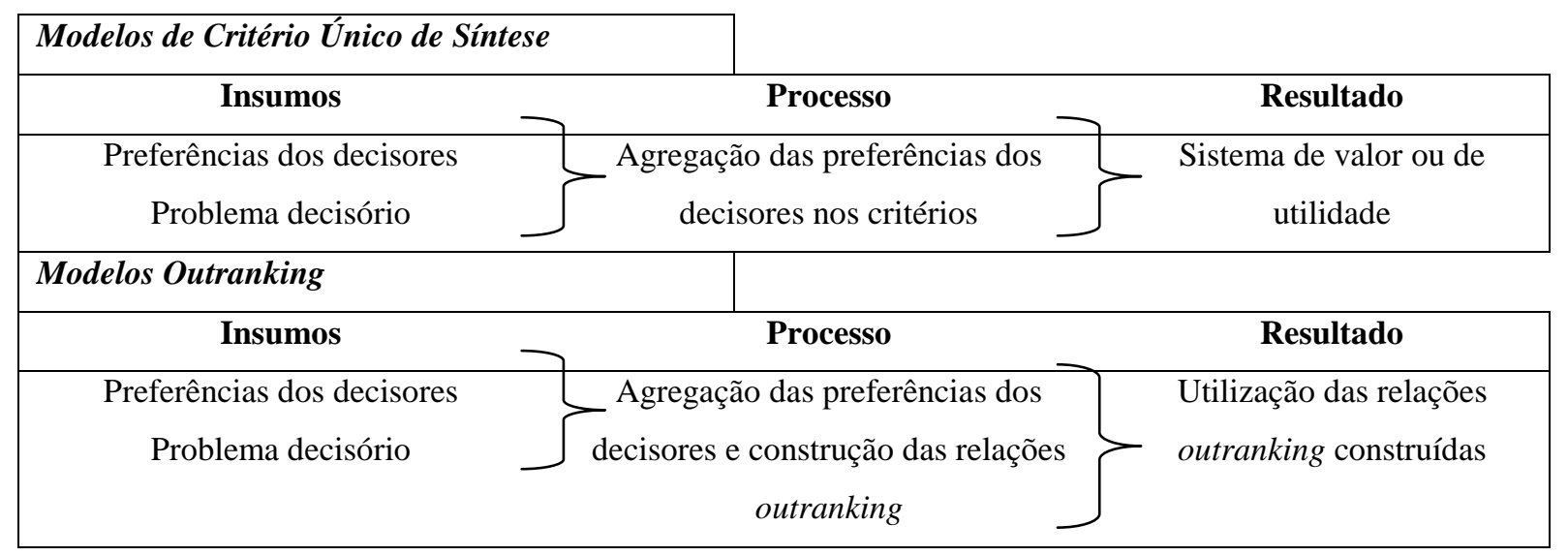

Figura 1. Fluxo de Processamento dos MMAD.

Fonte: Adaptado de Siskos, Y., \& Spyridakos, A. (1999). Intelligent multicriteria decision support: overview and perspectives (p. 240). European Journal of Operational Research, 113(2), 236-246. doi: 10.1016/S0377-2217(98)00213-6

Os modelos outranking são orientados pela comparação direta entre as alternativas, cujos resultados apresentam principalmente o quanto uma determinada alternativa supera ou é superada por outra. Já os modelos de critério único de síntese apresentam uma pontuação global para cada alternativa, conformando sua função de valor ou utilidade, que culmina com a hierarquização das alternativas. Essa característica dos modelos de critério único de síntese favorece sua utilização em sistemas de classificação padronizada, que são voltados à avaliação de um grande número de alternativas. Esse tipo de aplicação geral não é favorecido pelo uso dos métodos outranking, que usualmente são aplicados a casos de maior singularidade e com um número menor de alternativas.

\section{Metodologia proposta}

O modelo proposto para hierarquização de áreas portuárias foi desenvolvido para aplicação nos portos organizados brasileiros, o que envolve mais de quarenta portos. As áreas a serem arrendadas em cada porto correspondem, em termos gerais, às alternativas decisórias que precisam ser avaliadas. Como o objetivo do sistema é avaliar a atratividade de cada área para, então, definir sua participação na absorção dos investimentos portuários, tem-se uma generalização da problemática de classificação do tipo $\gamma$. Isso decorre porque, conforme exposto no item Fundamentação Metodológica, o tipo $\gamma$ trata de classificação das alternativas, enquanto que os demais tipos $\alpha, \beta$ e $\delta$ trabalham com foco na seleção e descrição de alternativas, o que não corresponde a este caso. 
Como deduzido anteriormente a partir da Figura 1, esse tipo de problema decisório de classificação de um grande número de alternativas adapta-se melhor a modelos MMAD de critério decisório único de síntese, dentre os quais, destacam-se os métodos Analytic Hierarchy Process (AHP) (Saaty, 1990) e Mac Beth (Bana e Costa \& Vansnick, 1999).

Neste trabalho, optou-se pelo uso do método AHP no processo de modelagem, visto que sua utilização é frequente em outros tipos de problemas decisórios do setor portuário. O AHP é aplicado em duas etapas: construção da hierarquia e avaliação (Vargas, 1990). A adaptação dessas etapas gerais aos objetivos deste trabalho resultou em um modelo desenvolvido em cinco fases específicas:

1. Definição dos critérios globais de atratividade.

2. Identificação dos critérios específicos e de seus respectivos atributos de atratividade.

3. Estimação dos pesos dos elementos da estrutura: critérios globais, critérios específicos e atributos de atratividade.

4. Estimação da função de valor dos atributos de atratividade.

5. Apuração do resultado global de avaliação da atratividade de áreas portuárias.

As fases a e b referem-se à construção da hierarquia decisória, onde as informações são estruturadas, e as fases seguintes (c a e) referem-se à avaliação da hierarquia decisória.

Nas fases de estruturação das informações, a identificação dos critérios globais, dos critérios específicos e de seus respectivos atributos de atratividade, foi baseada nos estudos do National Oceanic and Atmospheric Administration (NOAA, 2009), da Queensland Water Commission (QWS, 2009). Tais informações foram sintetizadas em uma listagem (Lista 1), que foi submetida a um grupo de sete pesquisadores especialistas em transportes aquaviários, lotados no Programa de Pós-Graduação em Engenharia de Transportes da UnB e no CEFTRU, que, a partir de suas preferências e valores, propuseram uma listagem mais adequada à realidade brasileira, resultando na Lista 2 . O grupo de pesquisadores especialistas foi composto por dois professores doutores em engenharia de transporte, dois professores doutores em economia dos transportes e três professores doutores em engenharia de produção, com ênfase em transportes.

Por fim, um grupo de seis técnicos e gerentes de regulação da ANTAQ analisou ambas as listagens ( 1 e 2) e optou por ajustes e sintetizações que culminaram com uma listagem final (Lista 3), a qual representa a estruturação informacional do modelo estabelecido neste trabalho. $\mathrm{O}$ grupo de seis técnicos e gerentes de regulação foi composto por servidores de nível superior, quatro engenheiros civis, um engenheiro mecânico e um economista.

Posteriormente, o grupo de técnicos e especialistas da ANTAQ foi entendido como o grupo decisório primário, dessa maneira, todas as sessões de avaliação dos elementos informacionais, bem como a análise de aderência global do modelo, foram feitas com sua participação.

\section{Definição dos critérios globais de atratividade}

Nesta fase inicial da modelagem, considerando-se os elementos teóricos apresentados anteriormente, julgou-se adequado que a atratividade das áreas portuárias fosse avaliada segundo seus desempenhos nos critérios globais: localização da área, infraestrutura, acesso, gestão ambiental e características do solo e dos terrenos, conforme consta do esquema apresentado na Figura 2. Logo, os critérios de atratividade dizem respeito exclusivamente às áreas a serem arrendadas, não cabendo menção a critérios que impactem indistintamente o porto, tais como área de fundeio, canal de navegação, dragagem e manutenção. 


\begin{tabular}{|c|c|c|}
\hline & $C_{1}$ & Localização da Área \\
\hline \multirow{6}{*}{$\begin{array}{c}\text { Alocação dos } \\
\text { Investimentos } \\
\text { Portuários } \\
\text { às áreas } k \\
\end{array}$} & $C_{2}$ & Infraestrutura \\
\hline & & \\
\hline & $C_{3}$ & Acesso \\
\hline & & \\
\hline & $C_{4}$ & Gestão Ambiental \\
\hline & $C_{5}$ & Características do Solo e Terreno \\
\hline
\end{tabular}

Figura 2. Critérios Globais de Atratividade.

Fonte: Elaboração dos autores.

\section{Identificação dos critérios específicos e de seus respectivos atributos de atratividade}

Nessa fase, faz-se a descrição dos elementos que abrangem cada um dos critérios globais de atratividade através da identificação de seus critérios específicos (ou subcritérios) e de seus respectivos atributos.

\section{Critério global localização da área: critérios específicos e atributos}

A atratividade da localização da área $k$ é uma função de sua proximidade com o cais $\left(C_{11}\right)$, com a disponibilidade de área para futura ampliação $\left(C_{12}\right)$ e com a existência de barreiras físicas $\left(C_{13}\right)$. A descrição do critério específico à proximidade $\left(C_{11}\right)$ é feita através dos atributos:

. Proximidade menor que 500 metros.

. Proximidade entre 500 e 1000 metros.

. Proximidade maior que 1000 metros.

Os quais qualificam a atratividade como uma função da distância entre cada um dos critérios e a área $k$, atendendo à relação lógica de que quanto menor for essa distância maior será a atratividade da área. Já o critério específico da disponibilidade de área $\left(C_{12}\right)$ é medido pela existência ou não de área para futura ampliação, enquanto que o critério específico relativo à existência de barreiras físicas $\left(C_{13}\right)$ mede a atratividade da área em função dos custos de remoção dessas barreiras e da própria possibilidade de fazê-lo; sendo que a atratividade mais alta refere-se à remoção de baixo custo; e a atratividade mais baixa, à existência de barreiras físicas não removíveis. A Figura 3 sintetiza as informações descritoras do critério global de Localização da Área, dando ênfase nas ramificações de cada um dos critérios específicos.

\begin{tabular}{|c|c|c|c|c|c|}
\hline & & \multirow[b]{2}{*}{ Proximidade do cais } & $U_{111}$ & \multirow{2}{*}{$\begin{array}{c}\text { Proximidade }<500 \text { metros } \\
500<\text { Proximidade } \leq 1000 \mathrm{~m} \\
\end{array}$} \\
\hline & & $C_{11}$ & & $U_{112}$ & \\
\hline & & & & \multicolumn{2}{|r|}{ Proximidade $>1000$ metros } \\
\hline & & & & $U_{121}$ & Área disponível \\
\hline$C_{1}$ & Localização da Área & $C_{12}$ & Disponibilidade de área para futura ampliação & \multicolumn{2}{|r|}{ Área não-disponível } \\
\hline & & & & \multicolumn{2}{|r|}{ Remoção a custo baixo } \\
\hline & & $C_{13}$ & Barreiras físicas & \multicolumn{2}{|c|}{\begin{tabular}{l|l}
$U_{182}$ & Remoção a custo médio \\
\end{tabular}} \\
\hline & & & & \multirow{2}{*}{\multicolumn{2}{|c|}{$\begin{array}{l}\text { Remoção a custo alto } \\
\text { Barreira não removível }\end{array}$}} \\
\hline & & & & & \\
\hline
\end{tabular}

Figura 3. Critério Global Localização da Área: Critérios Específicos e Atributos de Atratividade. Fonte: Elaboração dos autores. 


\section{Critério global infraestrutura: critérios específicos e atributos}

No critério global de Infraestrutura, a atratividade da área $k$ é uma função da existência no local de saneamento básico $\left(C_{21}\right)$, energia e comunicação $\left(C_{22}\right)$ e de benfeitorias $\left(C_{23}\right)$. A descrição dos critérios específicos de infraestrutura $\left(C_{21}\right.$ a $\left.C_{23}\right)$ é feita através de atributos que qualificam a atratividade como uma função da disponibilidade de fatores na área. Dessa forma, a área é tão mais atrativa quanto maior for o leque de fatores de infraestrutura disponível no local. A Figura 4 sintetiza as informações descritoras do critério global de Infraestrutura, com ênfase nas ramificações de cada um dos critérios específicos.

\begin{tabular}{|c|c|c|c|c|c|}
\hline & & & & $U_{211}$ & Água potável e esgoto \\
\hline & & $C_{21}$ & \multirow{4}{*}{ Saneamento Básico } & $U_{212}$ & Água potável \\
\hline & & & & $U_{213}$ & \multirow{2}{*}{$\begin{array}{l}\text { Esgoto } \\
\text { Nenhum } \\
\end{array}$} \\
\hline & & & & $U_{214}$ & \\
\hline & & & & $U_{221}$ & Energia elétrica e comunicação \\
\hline $\mathrm{C}_{2}$ & \multirow[t]{7}{*}{ Infraestrutura } & $C_{22}$ & \multirow[t]{4}{*}{ Energia e comunicação } & $U_{222}$ & Energia elétrica \\
\hline & & & & $U_{223}$ & Comunicação \\
\hline & & & & $U_{224}$ & Nenhum deles \\
\hline & & & & $U_{231}$ & Escritórios e armazéns \\
\hline & & $C_{23}$ & \multirow[t]{3}{*}{ Benfeitorias existentes } & $U_{232}$ & Armazéns \\
\hline & & & & $U_{233}$ & Escritórios \\
\hline & & & & $U_{234}$ & Nenhum deles \\
\hline
\end{tabular}

Figura 4. Critério Global Infraestrutura: Critérios Específicos e Atributos de Atratividade.

Fonte: Elaboração dos autores.

\section{Critério global acesso: critérios específicos e atributos}

No critério global de Acesso, a atratividade da área $k$ é uma função da qualidade do acesso terrestre à área $\left(C_{31}\right)$, do acesso hidroviário $\left(C_{32}\right)$, do acesso dutoviário $\left(C_{33}\right)$ e da disponibilidade de linha de cais $\left(C_{34}\right)$. No critério específico de acesso à área $\left(C_{31}\right)$, a atratividade é mais alta quando o acesso dispõe da combinação dos modais ferroviário e rodoviário com asfalto e é mais baixa quando esses modais não dão acesso à área. Já atratividade nos critérios específicos $C_{32}$ e $C_{33}$ diz respeito à disponibilidade dos acessos hidroviário e dutoviário, respectivamente. Para o critério específico de disponibilidade de linha de cais $\left(C_{34}\right)$ a área é tão mais atrativa quanto maior for o comprimento da linha. A Figura 5 sintetiza as informações descritoras do critério global Acesso, com ênfase nas ramificações de cada um dos critérios específicos.

\begin{tabular}{|c|c|c|c|c|c|}
\hline & & & & $U_{311}$ & Acesso rodoferroviário com asfalto \\
\hline & & & & $U_{312}$ & Acesso rodoferroviário sem asfalto \\
\hline & & & & $U_{313}$ & Acesso rodoviário com asfalto \\
\hline & & $C_{31}$ & Acesso terrestre à área & $U_{314}$ & Acesso ferroviário \\
\hline & & & & $U_{315}$ & Acesso rodoviário sem asfalto \\
\hline & & & & $U_{316}$ & Sem acesso \\
\hline & & $C_{32}$ & Acesso hidroviário à área & $U_{321}$ & Acesso hidroviário \\
\hline & & & & $U_{322}$ & Sem acesso \\
\hline$C_{3}$ & Acesso & $C_{33}$ & Acesso dutoviário à área & $\frac{U_{331}}{2}$ & Acesso dutoviário \\
\hline & & & & $U_{332}$ & Sem acesso \\
\hline & & & & $U_{341}$ & Linha $>900 \mathrm{~m}$ \\
\hline & & & & $U_{342}$ & $700<$ Linha $\leq 900 \mathrm{~m}$ \\
\hline & & $C_{34}$ & Disponibilidade de linha de cais & $U_{343}$ & $500<$ Linha $\leq 700 \mathrm{~m}$ \\
\hline & & & & $U_{344}$ & $300<$ Linha $\leq 500 \mathrm{~m}$ \\
\hline & & & & $U_{345}$ & Linha $<300 \mathrm{~m}$ \\
\hline
\end{tabular}

Figura 5. Critério Global Acesso: Critérios Específicos e Atributos de Atratividade.

Fonte: Elaboração dos autores. 


\section{Critério global gestão ambiental: critérios específicos e atributos}

No critério global de Gestão Ambiental, a atratividade da área $k$ é uma função da proximidade do local à área de proteção ambiental $\left(C_{41}\right)$ e da existência de passivo ambiental $\left(C_{42}\right)$. No critério específico de proximidade à área de proteção ambiental $\left(C_{41}\right)$, a atratividade da área $k$ é medida em função de sua distância até a área de proteção, sendo que quanto maior for essa distância, melhor. $\mathrm{O}$ critério específico relativo ao passivo ambiental $\left(C_{42}\right)$ é descrito em função de que sua existência confere menor atratividade à área, pois terá de ser remediado pelo arrendatário. A Figura 6 sintetiza as informações descritoras do critério global Gestão Ambiental, com ênfase nas ramificações de cada um dos critérios específicos.

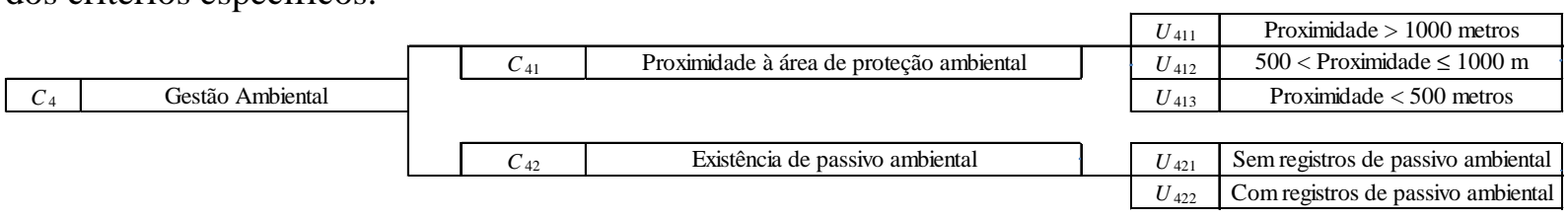

Figura 6. Critério Global Gestão Ambiental: Critérios Específicos e Atributos de Atratividade. Fonte: Elaboração dos autores.

\section{Critério global características do solo e terreno: critérios específicos e atributos}

No critério global de Características do Solo e Terreno, a atratividade da área $k$ é uma função da altimetria e solo $\left(C_{51}\right)$ e da forma do terreno $\left(C_{52}\right)$. No critério específico da altimetria e solo $\left(C_{51}\right)$, a atratividade da área $k$ é medida em função da combinação dessas duas características, sendo que as áreas de altimetria plana e solo rígido são as de maior atratividade, enquanto que as áreas de altimetria ondulada e solo inconsistente são as de menor atratividade. Para o critério específico à forma do terreno $\left(C_{52}\right)$, a atratividade é medida em função de sua regularidade. A Figura 7 sintetiza as informações descritoras do critério global de Características do Solo e Terreno, com ênfase nas ramificações de cada um dos critérios específicos.

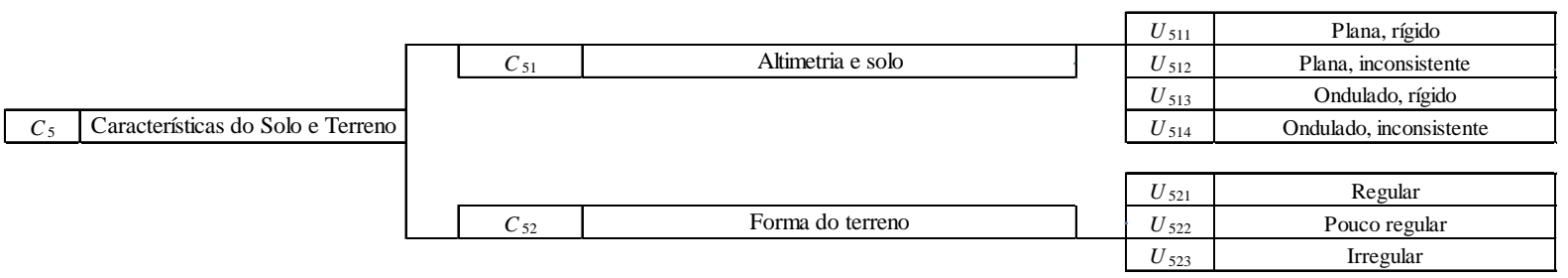

Figura 7. Critério Global Características do Solo e Terreno: Critérios Específicos e Atributos de Atratividade.

Fonte: Elaboração dos autores.

\section{Estimação dos pesos dos elementos da estrutura: critérios globais, critérios específicos e atributos de atratividade}

Após a especificação dos elementos e da estrutura hierárquica do modelo, inicia-se a fase de estimação dos pesos ou índices de importância relativa dos critérios globais, critérios específicos e atributos de atratividade. Saaty (1990) propôs o Processo de Análise Hierárquica (AHP - Analytic Hierarchy Process) para solucionar problemas decisórios que envolvem múltiplos critérios. Usando uma estrutura hierárquica sistemática, os critérios de estimação complexa podem ser representados, claramente e de forma definitiva, a partir das expressões de preferências e valores dos decisores.

Considere-se que os critérios $C_{1}, \ldots, C_{i}, \ldots, C_{j}, \ldots, C_{n}$ tenham algum nível na hierarquia e desejase obter seus pesos, $w_{1}, \ldots, w_{i}, \ldots, w_{j}, \ldots, w_{n}$ sobre alguns elementos no próximo nível. 
Considere-se que $a_{i j}, i, j=1,2, \ldots, n$ representa as intensidades de importância de $C_{i}$ quando comparado com $C_{j}$, e que pode-se representar a escala de importância comparativa de $C_{i}$ e $C_{j}$, segundo o conteúdo da Tabela 3 .

Tabela 3

Escala de Julgamento de Importância do AHP

\begin{tabular}{|c|c|c|}
\hline Escala & Definição & Descrição \\
\hline 1 & Importância igual & $\begin{array}{l}\text { Dois critérios potenciais contribuem igualmente para o } \\
\text { objetivo. }\end{array}$ \\
\hline 3 & $\begin{array}{l}\text { Importância fraca de uma } \\
\text { sobre a outra }\end{array}$ & $\begin{array}{l}\text { A experiência e o julgamento favorecem levemente um critério } \\
\text { em relação ao outro. }\end{array}$ \\
\hline 5 & Importância forte & $\begin{array}{l}\text { A experiência e o julgamento favorecem fortemente um } \\
\text { critério em relação ao outro. }\end{array}$ \\
\hline 7 & Importância muito forte & $\begin{array}{l}\text { Um critério é fortemente favorecido em relação ao outro e sua } \\
\text { dominância é demonstrada na prática. }\end{array}$ \\
\hline 9 & Importância absoluta & $\begin{array}{l}\text { A evidência favorecendo um critério em relação ao outro é do } \\
\text { mais alto grau de certeza. }\end{array}$ \\
\hline $2,4,6,8$ & $\begin{array}{l}\text { Valores intermediários entre } \\
\text { dois julgamentos adjacentes }\end{array}$ & Quando é necessária uma condição de compromisso. \\
\hline Recíprocos & \multicolumn{2}{|c|}{$\begin{array}{l}\text { Se } C_{i} \text { tem uma das intensidades de importância ou de preferência de } 1 \text { a } 9 \text { quando comparado } \\
\text { com } C_{j} \text {, então, } C_{j} \text { tem o valor recíproco quando comparado com } C_{j} \text {. }\end{array}$} \\
\hline
\end{tabular}

Nota. Fonte: Adaptado de Saaty, T. L. (1990). How to make a decision: the analytic hierarchy process (p. 15). European Journal of Operational Research, 48(1), 9-26. doi: 10.1016/0377-2217(90)90057-I

A matriz dos elementos $a_{i j}$ é denotada por $\mathbf{A}$, ou

$$
\mathbf{A}=\left[\begin{array}{ccccc}
a_{11} & \cdots & a_{1 j} & \cdots & a_{1 n} \\
\vdots & \ddots & \vdots & \ddots & \vdots \\
a_{i 1} & \cdots & a_{i j} & \cdots & a_{i n} \\
\vdots & \ddots & \vdots & \ddots & \vdots \\
a_{n 1} & \cdots & a_{n j} & \cdots & a_{n n}
\end{array}\right]_{n \times n}
$$

onde $a_{j i}$ é o recíproco de $a_{i j}$, ou $a_{j i}=1 / a_{i j}$, sendo que $a_{i j}=w_{i} / w_{j}, i, j=1,2, \ldots, n$.

A resolução da matriz A pode ser feita mediante o cálculo do autovalor $v_{i}$ :

$$
v_{i}=\left(\prod_{j=1}^{n} a_{i j}\right)^{1 / n}
$$

cuja normalização resulta no autovetor de prioridades $\mathbf{w}$, que expressa as importâncias relativas (pesos) de cada um dos critérios globais, critérios específicos e atributos, cujo cálculo individual segue a forma: 


$$
\mathbf{w}_{n \times 1}=\left[\begin{array}{c}
w_{1}=v_{1} / \sum_{i=1}^{n} v_{i} \\
w_{2}=v_{2} / \sum_{i=1}^{n} v_{i} \\
w_{3}=/ \sum_{3}^{n} v_{i=1}^{n} \\
\vdots \\
w_{n}=v_{n} / \sum_{i=1}^{n} v_{i}
\end{array}\right]
$$

Consequentemente, quando a matriz A é multiplicada pelo vetor formado por cada ponderação $\mathbf{w}=\left(w_{1}, w_{2}, \ldots, w_{n}\right)^{T}$, obtém-se

$$
\mathbf{A} \mathbf{w}=\left[\begin{array}{ccccc}
w_{1} / w_{1} & \cdots & w_{1} / w_{j} & \cdots & w_{1} / w_{n} \\
\vdots & \vdots & \vdots & \vdots & \vdots \\
w_{i} / w_{1} & \cdots & w_{i} / w_{j} & \cdots & w_{i} / w_{n} \\
\vdots & \vdots & \vdots & \vdots & \vdots \\
w_{n} / w_{1} & \cdots & w_{n} / w_{j} & \cdots & w_{n} / w_{n}
\end{array}\right]_{n \times n}\left[\begin{array}{l}
w_{1} \\
\vdots \\
w_{j} \\
\vdots \\
w_{n}
\end{array}\right]_{n \times 1}=n\left[\begin{array}{l}
w_{1} \\
\vdots \\
w_{j} \\
\vdots \\
w_{n}
\end{array}\right]_{n \times 1}=n \mathbf{w}
$$

Como $a_{i j}$ é uma classificação subjetiva dada pelos decisores, deve existir uma distância entre ela e os valores atuais de $w_{i} / w_{j}$. Logo, a relação $\mathbf{A w}=n \mathbf{w}$ não pode ser calculada diretamente. Para que isso fosse feito Saaty (1991) sugeriu o cálculo do autovalor máximo

$$
\lambda_{\max }=\frac{1}{n}\left(\frac{w_{1}}{w_{1}}+\frac{w_{2}}{w_{2}}+\cdots+\frac{w_{n}}{w_{n}}\right)
$$

da matriz A para substituir $n$. Então, tem-se que

$$
A w=\lambda_{\max } w
$$

Por este método, pode-se obter o vetor característico, que corresponde ao vetor de prioridades. Além disso, Saaty (1990) também sugeriu o índice de consistência

$$
I C=\frac{\lambda_{\max }-n}{n-1}
$$

e a taxa de consistência

$$
T C=\frac{I C}{C A}
$$

sendo que $C A$ refere-se à consistência aleatória (maiores detalhes sobre $C A$, vide Lane \& Verdini, 1989). Em geral, é satisfatório e aceito se o valor de IC estiver em torno de 0,10 e o valor do CA for menor que 0,10 .

Adaptando-se esses elementos de avaliação à estrutura deste trabalho, tem-se $k$ áreas do porto que são candidatas ao arrendamento $\left(A_{1}, A_{2}, \ldots, A_{k}\right), M$ critérios globais de avaliação, $\sum_{m=1}^{m} \sum_{n=1}^{n} C_{m n}$ critérios específicos $\left(C_{12}, C_{21}, \ldots, C_{m n}, \ldots, . C_{M N}\right), \sum_{m=1}^{M} \sum_{n=1}^{N} \sum_{o=1}^{O} U_{m n o}$ atributos de atratividade para cada 
critério específico $\left(U_{111}, U_{112}, \ldots, U_{m n o}, \ldots . . U_{M N O}\right), w_{m}, w_{m n}$ e $w_{m n o}$ são os pesos de $C_{m}, C_{m n}$ e $U_{m n o}$, respectivamente.

\section{Estimação da função de valor dos atributos de atratividade}

Para a avaliação dos atributos $\left(U_{m n o}\right)$, foi desenvolvido o seguinte procedimento de normalização, com o objetivo de se obter uma escala de atratividade entre 100 (máxima) e 0 (mínima):

$$
f u_{m n o}=\frac{w_{m n o}-w_{m n o}^{m i ́ n}}{w_{m n o}^{m a ́ x}-w_{m n o}^{m i n}}
$$

onde $f u_{m n o}$ é a função de valor do atributo analisado, $w_{m n o}$ é o peso do atributo analisado, $w_{m n o}{ }^{m i n} \mathrm{e}$ $w_{\text {mno }}{ }^{\max }$ referem-se ao menor e maior pesos dentre os atributos do critério específico $C_{m n}$, respectivamente.

Dessa forma, caso uma área $k$ tenha o desempenho de atratividade mínima em todos os critérios específicos, o valor de seu arrendamento será o valor correspondente à parcela fixa da equação (1), isto é, o valor calculado pela avaliação imobiliária.

\section{Apuração do resultado global de avaliação da atratividade de áreas portuárias}

Considere-se que a atratividade global da área $k$ é calculada pela soma ponderada do conjunto de pesos dos critérios globais, critérios específicos e funções de valor dos atributos

$$
V G_{k}=\sum_{m=1}^{M} \sum_{n=1}^{N} \sum_{o=1}^{O} w_{m} w_{m n} f u_{m n o}
$$

Como o valor de $V G_{k}$ não é normalizado, pode-se obter o vetor de pesos para o rateio do investimento entre as $k$ áreas do porto pelo ajuste

$$
\boldsymbol{\alpha}_{n \times 1}=\left[\begin{array}{c}
\alpha_{1}=V G_{1} / \sum_{k=1}^{n} V G_{k} \\
\alpha_{2}=V G_{2} / \sum_{k=1}^{n} V G_{k} \\
\alpha_{3}=V G_{3} / \sum_{k=1}^{n} V G_{k} \\
\alpha_{n}=V G_{n} / \sum_{k=1}^{n} V G_{k}
\end{array}\right]
$$

\section{Aplicação do modelo proposto para hierarquização de áreas portuárias com fins de rateio}

A primeira parte da aplicação da metodologia proposta corresponde à avaliação da estrutura hierárquica apresentada nos itens de definição dos critérios globais de atratividade e de identificação dos critérios específicos, bem como de seus respectivos atributos de atratividade, de acordo com os procedimentos quantitativos descritos anteriormente.

- Uma matriz dos critérios globais de atratividade.

- Cinco matrizes para os critérios específicos de atratividade.

- Quatorze matrizes para os atributos dos critérios específicos de atratividade. 


\section{Exemplo 1: avaliação dos critérios globais}

Na Figura 8, encontra-se a matriz de avaliação global dos critérios, de onde se extraiu o vetor de hierarquização dos critérios globais de atratividade, que atribui a maior atratividade à localização da área $(0,57)$, seguida da infraestrutura $(0,22)$, do acesso $(0,09)$, das características do solo e do terreno $(0,08)$ e da gestão ambiental $(0,04)$. A checagem da inconsistência resultou num índice de 0,0987 , que se situa dentro dos limites toleráveis. No preenchimento das matrizes, verifica-se que o número 1 corresponde à opção pelo valor da escala de atratividade da Tabela 3 e zero é aplicado às demais células a fim de que seja procedido o cálculo apropriado de multiplicação matricial.

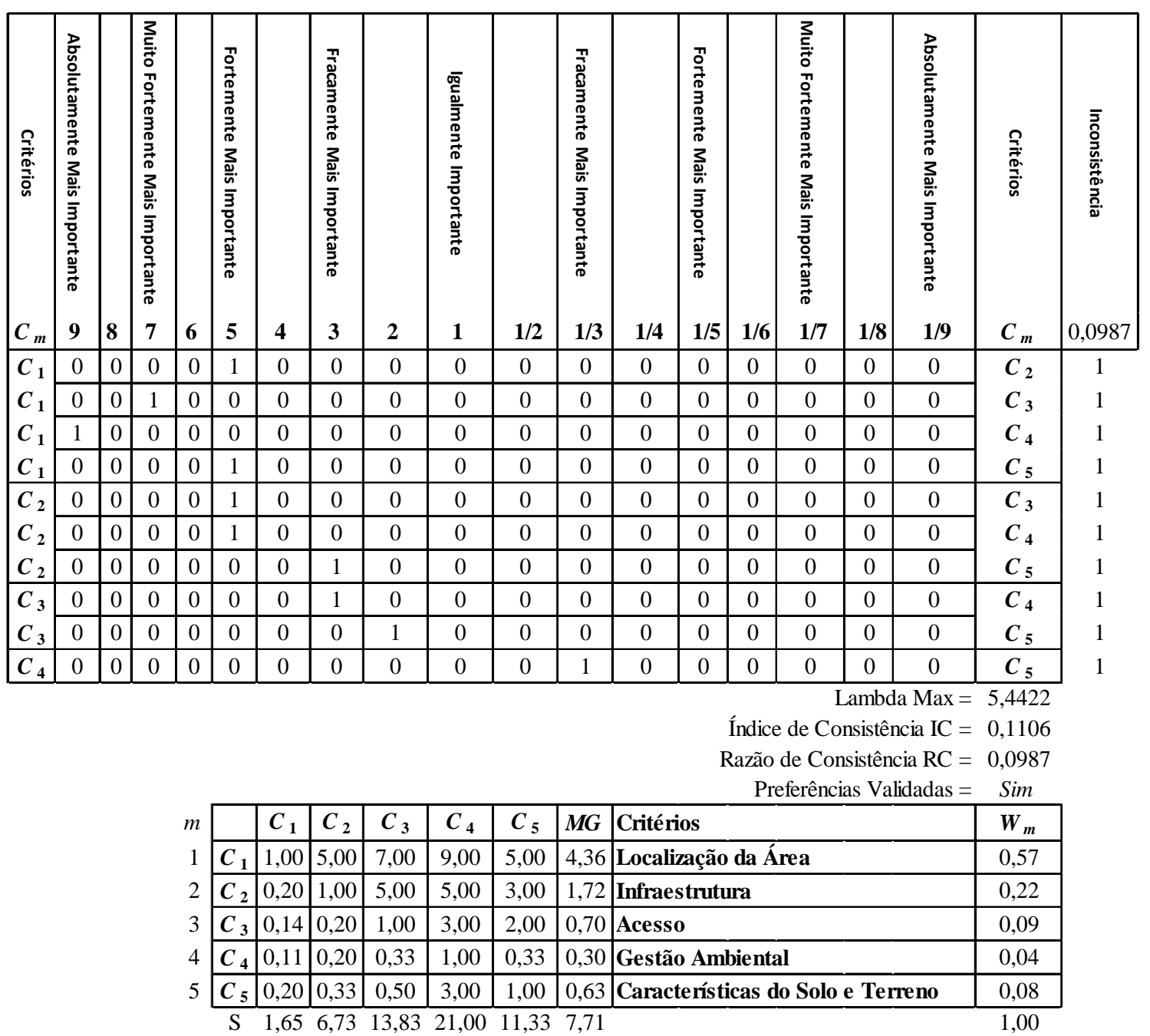

Figura 8. Avaliação dos Critérios Globais.

Fonte: Elaboração dos autores.

\section{Exemplo 2: avaliação local do critério global localização}

A Figura 9 mostra o exemplo de uma das matrizes de avaliação dos critérios específicos construídas durante a avaliação. Nessa matriz, foi calculado o vetor de hierarquização dos critérios específicos de atratividade do critério global Localização, que atribui a maior atratividade à proximidade do cais $(0,77)$, seguida da disponibilidade de área para futura ampliação $(0,13)$ e da existência de barreiras físicas $(0,09)$. A checagem da inconsistência resultou num índice de 0,0930, que se situa dentro dos limites toleráveis. 


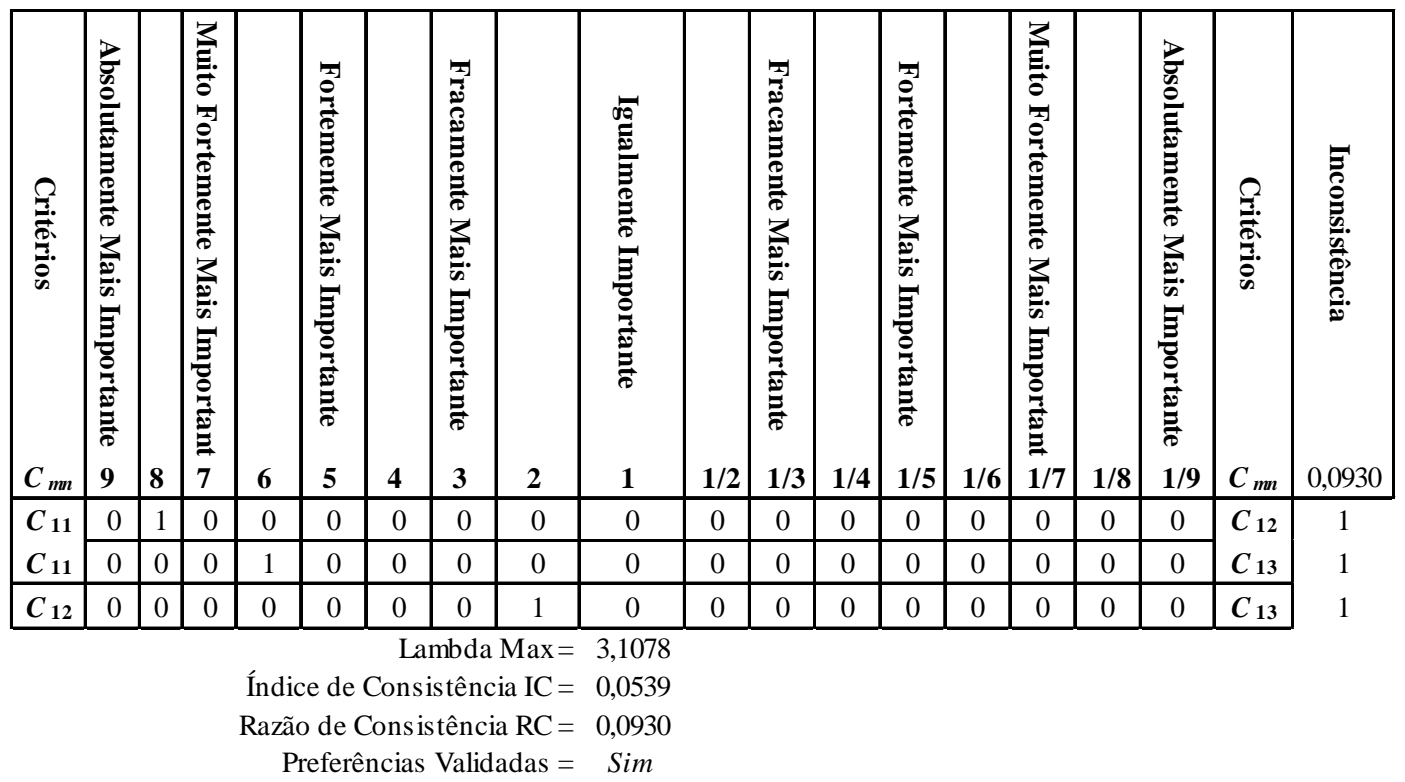

\begin{tabular}{|c|c|c|c|c|c|c|c|}
\hline & & $C_{11}$ & $C_{12}$ & $C_{13}$ & $M G$ & Critérios & $W_{m n}$ \\
\hline & $C_{11}$ & 1,00 & 8,00 & 6,00 & 3,63 & Proximidade do cais & 0,77 \\
\hline & $C_{12}$ & 0,13 & 1,00 & 2,00 & 0,63 & Disponibilidade de área para futura ampliação & 0,13 \\
\hline & $C_{13}$ & 0,17 & 0,50 & 1,00 & 0,44 & Barreiras físicas & 0,09 \\
\hline
\end{tabular}

Figura 9. Critério Localização - Avaliação dos Critérios Específicos.

Fonte: Elaboração dos autores.

\section{Exemplo 3: avaliação local dos atributos do critério proximidade do cais}

A Figura 10 ilustra o exemplo de uma das matrizes de avaliação dos atributos dos critérios específicos construídas durante a avaliação. Nessa matriz foi calculado o vetor de valoração dos atributos do critério específico de atratividade Proximidade do Cais, que atribui a maior atratividade à distância menor de 500 metros $(0,74)$, seguida da proximidade entre 500 e 1.000 metros $(0,19)$ e da proximidade acima de 1.000 metros $(0,06)$. A checagem da inconsistência resultou num índice de 0,0614 , que se situa dentro dos limites toleráveis. 


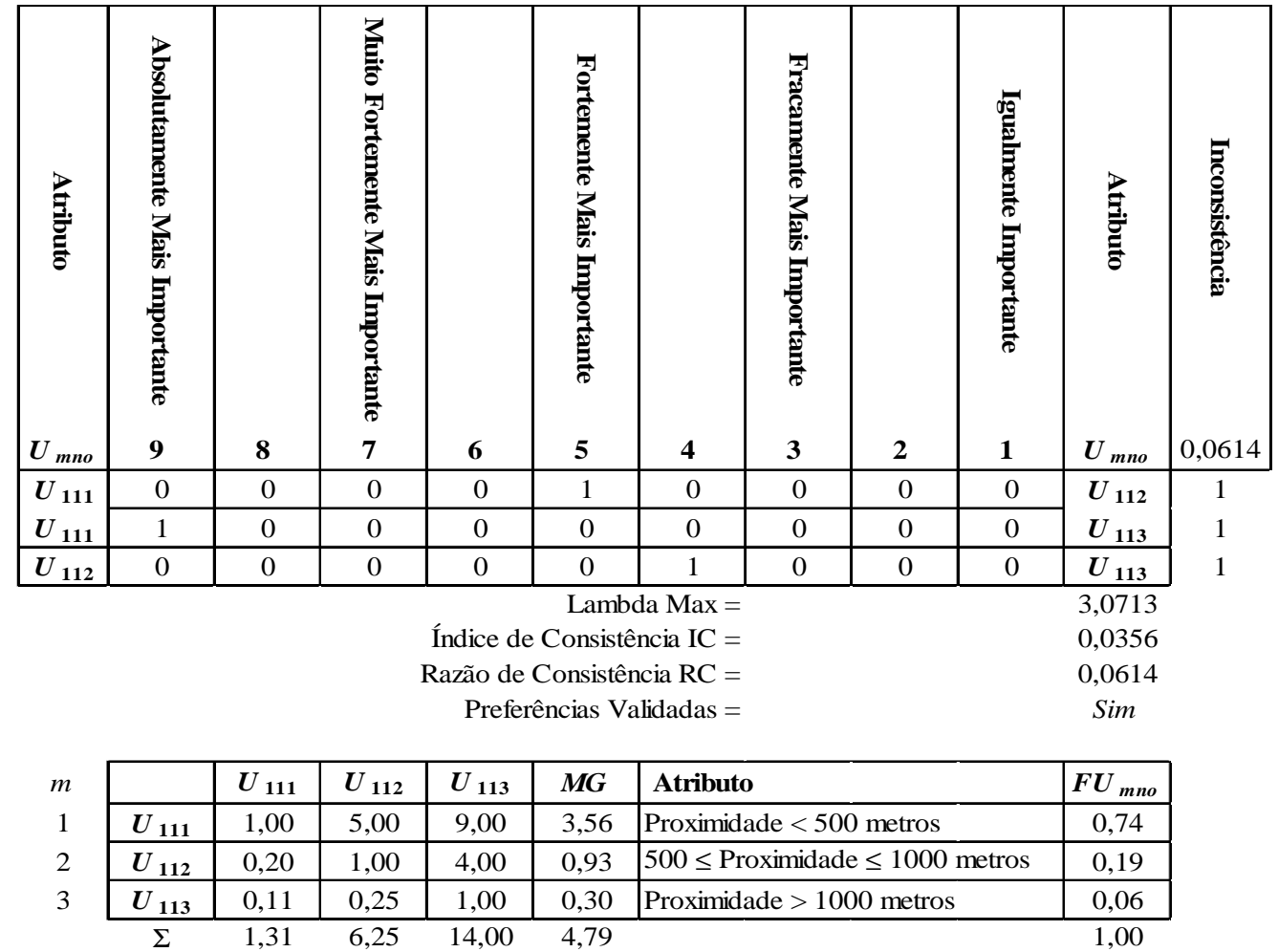

Figura 10. Critério Localização - Avaliação dos Atributos do Critério Específico Proximidade do Cais.

Fonte: Elaboração dos autores

Como o modelo foi elaborado para servir a um processo de classificação das alternativas, a estrutura hierárquica considera todas as possibilidades de desempenho possíveis para as áreas portuárias. Dessa forma, a classificação final das áreas portuárias e o cálculo do vetor de pesos para rateio dos investimentos tornam-se acessíveis, como pode ser visto na Tabela 4.

A Tabela 4 apresenta os resultados de uma aplicação hipotética do modelo ao caso de um porto que possui cinco áreas para arrendamento à iniciativa privada, com as seguintes características:

- Áreas 1 e 5: possuem atratividade máxima em todos os critérios específicos.

- Área 2: possui atratividade intermediária ou nula em todos os critérios específicos.

- Áreas 3 e 4: possuem atratividade mínima em todos os critérios específicos.

$\mathrm{Na}$ Tabela 4, constam todas as informações qualitativas (estrutura hierárquica) e quantitativas (avaliação das matrizes e funções de valor) necessárias para o entendimento total do processo de avaliação. No preenchimento da planilha, basta que se atribua 1 (um) à presença do atributo e 0 (zero) à ausência do atributo, que todos os cálculos são feitos instantaneamente por funções matriciais predefinidas da planilha eletrônica Excel.

O modelo capturou devidamente a atratividade das áreas hipotéticas, pois apresentou os seguintes resultados finais:

- Áreas 1 e 5: como possuem atratividade máxima em todos os critérios específicos, cada uma delas apresentou um resultado final de 100 pontos, o que equivale à absorção unitária de parcela equivalente a $45,9 \%$ do valor do investimento total. 
- Área 2: como possui atratividade intermediária ou nula em todos os critérios específicos, apresentou uma pontuação final de 17,68 pontos, correspondendo à absorção de $8,1 \%$ do valor do investimento total.

- Áreas 3 e 4: como possuem atratividade mínima em todos os critérios específicos, apresentaram pontuações finais nulas, o que fará com que o valor de seu arrendamento corresponda somente à parte fixa da equação (1), pois não absorverão nenhuma parcela do investimento total. 
Tabela 4

\section{Síntese da Avaliação do Desempenho das Áreas}

\begin{tabular}{|c|c|c|c|c|c|c|c|c|c|c|c|c|c|}
\hline $\begin{array}{c}\text { Critério } \\
C_{m} \\
\text { Sub-Critério } \\
C_{m n} \\
\end{array}$ & $\begin{array}{c}\text { Peso } \\
w_{m} \\
\text { Peso } \\
w_{m n} \\
\end{array}$ & Descritor & $\begin{array}{c}\text { Produto } \\
\boldsymbol{w}_{m} \boldsymbol{w}_{m n}\end{array}$ & $\begin{array}{c}\text { Atributo } \\
\boldsymbol{u}_{m n o}\end{array}$ & $\begin{array}{c}\text { Peso } \\
\boldsymbol{u}_{m n o}\end{array}$ & $\begin{array}{c}\text { Função } \\
f u_{m n o}\end{array}$ & $\begin{array}{c}\text { Função } \\
\text { Valor } \\
w_{m} w_{m n} f u_{m n o}\end{array}$ & Descritor & $\begin{array}{l}\text { Áreas } \\
A_{k} \\
\quad A_{1} \\
\end{array}$ & uárias & $A_{3}$ & $A_{4}$ & $A_{5}$ \\
\hline$C_{1}$ & $\mathbf{0 , 5 7}$ & LOCALIZAÇÃO DA ÁREA & & & & & & & & & & & \\
\hline \multirow[t]{3}{*}{$C_{11}$} & 0,77 & Proximidade do Cais & 0,44 & $U_{111}$ & 0,74 & 100,00 & 43,6966 & Proximidade $<500$ metros & 1 & & & & 1 \\
\hline & & & & $U_{112}$ & 0,19 & 19,22 & 8,3990 & $500 \leq$ Proximidade $\leq 1000 \mathrm{~m}$ & & 1 & & & \\
\hline & & & & $U_{113}$ & 0,06 & 0,00 & 0,0000 & Proximidade $>1000$ metros & & & 1 & 1 & \\
\hline \multirow[t]{2}{*}{$C_{12}$} & 0,13 & Disponibilidade de área para futura ampliação & 0,08 & $U_{121}$ & 0,89 & 100,00 & 7,5744 & Área disponível & 1 & & & & 1 \\
\hline & & & & $U_{122}$ & 0,11 & 0,00 & 0,0000 & Área não-disponível & & 1 & 1 & 1 & \\
\hline \multirow[t]{4}{*}{$C_{13}$} & 0,09 & Barreiras físicas & 0,05 & $U_{131}$ & 0,70 & 100,00 & 5,2518 & Remoção a custo baixo & 1 & & & & 1 \\
\hline & & & & $U_{132}$ & 0,17 & 17,75 & 0,9320 & Remoção a custo médio & & 1 & & & \\
\hline & & & & $U_{133}$ & 0,07 & 3,00 & 0,1576 & Remoção a custo alto & & & & & \\
\hline & & & & $U_{134}$ & 0,05 & 0,00 & 0,0000 & Barreira não-removível & & & 1 & 1 & \\
\hline$C_{2}$ & 0,22 & INFRAESTRUTURA & & & & & & & & & & & \\
\hline \multirow[t]{4}{*}{$C_{21}$} & 0,80 & Saneamento Básico & 0,18 & $U_{211}$ & 0,70 & 100,00 & 17,7776 & Água potável e esgoto & 1 & & & & 1 \\
\hline & & & & $U_{212}$ & 0,17 & 17,54 & 3,1178 & Água potável & & 1 & & & \\
\hline & & & & $U_{213}$ & 0,07 & 2,42 & 0,4306 & Esgoto & & & & & \\
\hline & & & & $U_{214}$ & 0,06 & 0,00 & 0,0000 & Nenhum & & & 1 & 1 & \\
\hline \multirow[t]{4}{*}{$C_{22}$} & 0,14 & Energia e comunicação & 0,03 & $U_{221}$ & 0,70 & 100,00 & 3,0816 & Energia elétrica e comunicação & 1 & & & & 1 \\
\hline & & & & $U_{222}$ & 0,17 & 17,75 & 0,5468 & Energia elétrica & & 1 & & & \\
\hline & & & & $U_{223}$ & 0,07 & 3,00 & 0,0925 & Comunicação & & & & & \\
\hline & & & & $U_{224}$ & 0,05 & 0,00 & 0,0000 & Nenhum deles & & & 1 & 1 & \\
\hline \multirow[t]{4}{*}{$C_{23}$} & 0,06 & Benfeitorias existentes & 0,01 & $U_{231}$ & 0,70 & 100,00 & 1,4244 & Escritórios e armazéns & 1 & & & & 1 \\
\hline & & & & $U_{232}$ & 0,17 & 17,75 & 0,2528 & Armazéns & & 1 & & & \\
\hline & & & & $U_{233}$ & 0,07 & 3,00 & 0,0427 & Escritórios & & & & & \\
\hline & & & & $U_{234}$ & 0,05 & 0,00 & 0,0000 & Nenhum deles & & & 1 & 1 & \\
\hline
\end{tabular}




\section{Tabela 4 (continuação)}

\begin{tabular}{|c|c|c|c|c|c|c|c|c|c|c|c|c|c|}
\hline $\begin{array}{c}\text { Critério } \\
C_{m} \\
\text { Sub-Critério } \\
C_{m n} \\
\end{array}$ & $\begin{array}{c}\text { Peso } \\
w_{m} \\
\text { Peso } \\
w_{m n} \\
\end{array}$ & Descritor & $\begin{array}{c}\text { Produto } \\
w_{m} w_{m n}\end{array}$ & $\begin{array}{c}\text { Atributo } \\
\boldsymbol{u}_{m n o}\end{array}$ & $\begin{array}{c}\text { Peso } \\
\boldsymbol{u}_{m n o}\end{array}$ & $\begin{array}{c}\text { Função } \\
f u_{m n o}\end{array}$ & $\begin{array}{c}\text { Função } \\
\text { Valor } \\
w_{m} w_{m n} f u_{m n o}\end{array}$ & Descritor & $\begin{array}{l}\text { Área } \\
A_{k} \\
\quad A_{1} \\
\end{array}$ & uárias & $A_{3}$ & $A_{4}$ & $A_{5}$ \\
\hline$C_{3}$ & 0,09 & ACESSO & & & & & & & & & & & \\
\hline \multirow[t]{6}{*}{$C_{31}$} & 0,70 & Acesso terrestre à área & 0,06 & $U_{311}$ & 0,44 & 100,00 & 6,3945 & Acesso rodoferroviário com asfalto & 1 & & & & 1 \\
\hline & & & & $U_{312}$ & 0,22 & 45,88 & 2,9335 & Acesso rodoferroviário sem asfalto & & 1 & & & \\
\hline & & & & $U_{313}$ & 0,17 & 33,90 & 2,1677 & Acesso rodoviário com asfalto & & & & & \\
\hline & & & & $U_{314}$ & 0,08 & 12,50 & 0,7990 & Acesso ferroviário & & & & & \\
\hline & & & & $U_{315}$ & 0,06 & 5,89 & 0,3767 & Acesso rodoviário sem asfalto & & & & & \\
\hline & & & & $U_{316}$ & 0,03 & 0,00 & 0,0000 & Sem acesso & & & 1 & 1 & \\
\hline \multirow[t]{2}{*}{$C_{32}$} & 0,17 & Acesso hidroviário à área & 0,02 & $U_{321}$ & 0,83 & 100,00 & 1,5443 & Acesso disponível & 1 & & & & 1 \\
\hline & & & & $U_{322}$ & 0,17 & 0,00 & 0,0000 & Sem acesso & & 1 & 1 & 1 & \\
\hline \multirow[t]{2}{*}{$C_{33}$} & 0,07 & Acesso dutoviário à área & 0,01 & $U_{331}$ & 0,83 & 100,00 & 0,6748 & Acesso disponível & 1 & & & & 1 \\
\hline & & & & $U_{332}$ & 0,17 & 0,00 & 0,0000 & Sem acesso & & 1 & 1 & 1 & \\
\hline \multirow[t]{5}{*}{$C_{34}$} & 0,05 & Disponibilidade de linha de cais & 0,00 & $U_{341}$ & 0,60 & 100,00 & 0,4979 & Linha $>900 \mathrm{~m}$ & 1 & & & & 1 \\
\hline & & & & $U_{342}$ & 0,20 & 28,09 & 0,1398 & $700<$ Linha $\leq 900 \mathrm{~m}$ & & 1 & & & \\
\hline & & & & $U_{343}$ & 0,10 & 10,27 & 0,0511 & $500<$ Linha $\leq 700 \mathrm{~m}$ & & & & & \\
\hline & & & & $U_{344}$ & 0,06 & 2,34 & 0,0117 & $300<$ Linha $\leq 500 \mathrm{~m}$ & & & & & \\
\hline & & & & $U_{345}$ & 0,05 & 0,00 & 0,0000 & Linha $<300 \mathrm{~m}$ & & & 1 & 1 & \\
\hline$C_{4}$ & $\mathbf{0 , 0 4}$ & GESTÃO AMBIENTAL & & & & & & & & & & & \\
\hline \multirow[t]{3}{*}{$C_{41}$} & 0,17 & Proximidade à área de proteção ambiental & 0,01 & $U_{411}$ & 0,72 & 100,00 & 0,6503 & Proximidade $>1000$ metros & 1 & & & & 1 \\
\hline & & & & $U_{412}$ & 0,19 & 16,94 & 0,1102 & $500 \leq$ Proximidade $\leq 1000 \mathrm{~m}$ & & 1 & & & \\
\hline & & & & $U_{413}$ & 0,09 & 0,00 & 0,0000 & Proximidade $<500$ metros & & & 1 & 1 & \\
\hline \multirow[t]{2}{*}{$C_{42}$} & 0,83 & Existência de passivo ambiental & 0,03 & $U_{421}$ & 0,83 & 100,00 & 3,2516 & Sem registros de passivo ambiental & 1 & & & & 1 \\
\hline & & & & $U_{422}$ & 0,17 & 0,00 & 0,0000 & Com registros de passivo ambiental & & 1 & 1 & 1 & \\
\hline
\end{tabular}


Tabela 4 (continuação)

\begin{tabular}{|c|c|c|c|c|c|c|c|c|c|c|c|c|c|}
\hline $\begin{array}{c}\text { Critério } \\
C_{m} \\
\text { Sub-Critério } \\
C_{m n} \\
\end{array}$ & $\begin{array}{c}\text { Peso } \\
w_{m} \\
\text { Peso } \\
w_{m n} \\
\end{array}$ & Descritor & $\begin{array}{c}\text { Produto } \\
w_{m} w_{m n}\end{array}$ & $\begin{array}{c}\text { Atributo } \\
\boldsymbol{u}_{m n o}\end{array}$ & $\begin{array}{c}\text { Peso } \\
\boldsymbol{u}_{m n o}\end{array}$ & $\begin{array}{c}\text { Função } \\
f u_{m n o}\end{array}$ & $\begin{array}{c}\text { Função } \\
\text { Valor } \\
w_{m} w_{m n} f u_{m n o}\end{array}$ & Descritor & $\begin{array}{l}\text { Áreas Po } \\
A_{k} \\
\quad A_{1} \\
\end{array}$ & $\begin{array}{l}\text { tuárias } \\
\qquad A_{2} \\
\end{array}$ & $A_{3}$ & $A_{4}$ & $A_{5}$ \\
\hline$C_{5}$ & $\mathbf{0 , 0 8}$ & CARACTERÍSTICAS DO SOLO E TERREN & & & & & & & & & & & \\
\hline \multirow[t]{4}{*}{$C_{51}$} & 0,75 & Altimetria e solo & 0,06 & $U_{511}$ & 0,70 & 100,00 & 6,1352 & Plana, rígido & 1 & & & & 1 \\
\hline & & & & $U_{512}$ & 0,17 & 17,75 & 1,0887 & Plana, inconsistente & & 1 & & & \\
\hline & & & & $U_{513}$ & 0,07 & 3,00 & 0,1841 & Ondulado, rígido & & & & & \\
\hline & & & & $U_{514}$ & 0,05 & 0,00 & 0,0000 & Ondulado, inconsistente & & & 1 & 1 & \\
\hline \multirow[t]{7}{*}{$C_{52}$} & 0,25 & Forma do terreno & 0,02 & $U_{521}$ & 0,79 & 100,00 & 2,0451 & Regular & 1 & & & & 1 \\
\hline & & & & $U_{522}$ & 0,13 & 7,70 & 0,1575 & Pouco regular & & 1 & & & \\
\hline & & & & $U_{523}$ & 0,08 & 0,00 & 0,0000 & Irregular & & & 1 & 1 & \\
\hline & & & & & & & & Atratividade da Área $\left(V G_{k}\right)$ & 100,00 & 17,68 & 0,00 & 0,00 & 100,00 \\
\hline & & & & & & & & Vetor de Proporções de Rateio $\left(\alpha_{k}\right)$ & $45,9 \%$ & $8,1 \%$ & $0,0 \%$ & $0,0 \%$ & $45,9 \%$ \\
\hline & & & & & & & & Número de Avaliações & 14 & 14 & 14 & 14 & 14 \\
\hline & & & & & & & & Prova do Número de Avaliações & $\mathrm{OK}$ & OK & OK & $\mathrm{OK}$ & OK \\
\hline
\end{tabular}

Nota. Fonte: Elaboração dos autores. 


\section{Considerações Finais}

Este artigo apresentou uma contribuição da área de métodos multicriteriais de análise de decisão (MMAD) a problemas de regulação, planejamento e gestão de portos.

O modelo multicriterial proposto foi sustentado por elementos técnico-científicos consistentes e desenvolvidos visando à definição da hierarquização das áreas portuárias a serem arrendadas à iniciativa privada. Os procedimentos culminaram com o cálculo da parcela dos investimentos portuários a ser absorvida por cada área, segundo critérios de atratividade.

O problema de avaliação considerado foi do tipo Gama, para o qual foi proposta uma estrutura classificatória, segundo a qual, a complexidade decisória foi coletivamente exaustiva no âmbito das possibilidades de atratividade das áreas disponíveis para arrendamento. Dessa forma, o modelo proposto permite que sejam avaliadas, num único sistema de avaliação, tantas áreas portuárias quantas houver, sem que haja prejuízo da qualidade de análise.

Ao final do processo de modelagem, dispôs-se de um instrumento devidamente convertido em planilha eletrônica, cuja facilidade de uso foi considerada como um fator decisivo por parte dos técnicos e gerentes de regulação da agência envolvida (ANTAQ), que afirmaram que passarão a adotar a ferramenta em vários de seus processos analíticos e de suporte à tomada de decisão.

Este tipo de pesquisa é de interesse dos órgãos governamentais encarregados de realizarem a regulação econômica do setor portuário e de concederem os espaços públicos dos portos à exploração da iniciativa privada.

Neste sentido, o trabalho oferece um modelo cientificamente robusto e de fácil aplicação prática para o uso nos processos de concessão de áreas nos portos públicos organizados brasileiros, que está fundamentado nas referências bibliográficas disponíveis sobre o tema e nas preferências e valores de um pequeno número de especialistas em transportes aquaviários e em regulação portuária. Essa característica limita o alcance deste modelo, embora apresente aos interessados uma proposta metodológica que orienta na elaboração de modelos similares.

Entende-se que o uso do método AHP, proveniente da escola americana, representa outra limitação ao presente estudo em razão de que há um grau considerável de subjetividade incorporada ao modelo. Essa limitação pode ser tratada em pesquisas futuras, mediante a conjugação de outras metodologias multicriteriais, tais como as famílias de modelos de apoio à decisão, considerando metodologias Outranking como ELimination Et Choix Traduisant la REalité (ELECTRE) e Preference Ranking Organisation METHod for Enrichment Evaluations (PROMETHEE), para a fixação do valor do arrendamento das áreas concedidas em portos.

Outras possibilidades de pesquisas futuras podem culminar com testes e customizações do modelo para uso em processos de concessão de áreas e serviços públicos em aeroportos, ferrovias, hidrovias e em outros tipos de infraestruturas operados por empresas privadas.

Corroborando essa perspectiva, vale ressaltar que a aplicação dos métodos multicriteriais atingiu seu auge no Brasil, na década de 1990. Entretanto há muitas áreas de atuação, sobretudo, no setor público, que demandam o desenvolvimento de modelos sustentados por esse tipo de ferramenta, que encontra suporte técnico-científico bastante consistente.

Artigo recebido em 11.03.2011. Aprovado em 05.06.2012. 


\section{Referências}

Avouris, N. M. (1995). Cooperating knowledge-based systems for environmental decision support. Knowledge-Based Systems, Elsevier, 8(1), 39-54. doi: 10.1016/0950-7051(94)00289-U

Bana e Costa, C. A., \& Vansnick, J. C. (1999). The MACBETH approach: basic ideas, software and an application. In N. Meskens \& M. D. Roubens (Eds.), Advances in decision analysis (pp. 131157). Dordrecht, Netherlands: Kluwer Academic Publishers.

Bana e Costa, C. A., \& Vincke, P. (1990). Multiple criteria decision aid: an overview. In C. A. Bana E Costa (Ed.), Readings in multicriteria decision aid (pp. 3-14). Berlin, Germany: Springer Verlag.

Button, K., \& Nijkamp, P. (1997). Environmental policy assessment and the usefulness of metaanalysis. Socio-Economic Planning Sciences, 31(3), 231-240. doi: 10.1016/S00380121(96)00034-1

Chou, C-C. (2010). AHP model for the container port choice in the multiple-ports region. Journal of Marine Science and Technology, 18(2), 221-232. doi: 10.1007/s00773-010-0108-8

Decreto n. 4.391, de 26 de setembro de 2002 (2002). Dispõe sobre arrendamento de áreas e instalações portuárias de que trata a Lei no 8.630, de 25 de fevereiro de 1993, cria o Programa Nacional de Arrendamento de Áreas e Instalações Portuárias, estabelece a competência para a realização dos certames licitatórios e a celebração dos contratos de arrendamento respectivos no âmbito do porto organizado, e dá outras providências. Brasília, DF. Recuperado de http://www.planalto.gov.br/ccivil_03/decreto/2002/d4391.htm

Funtowicz, S., Munda, G., \& Paruccini, M. (1990). The aggregation of environmental data using multicriteria methods. Environmetrics, 1(4), 353-368. doi: 10.1002/env.3170010405

Gray, P. C. R., Wiedemann, P. M., Schütz, H., Hallman, W. K., Feldman, D., \& Turner, R. (1996, outubro). The nature and challenges of environmental decision making. Background paper for Planning Workshop, National Center for Environmental Decision Making Research, Knoxville, TN, USA.

Grizzle, G. A. (1987). Pay for performance: can the analytic hierarchy process hasten the day in the public sector? Mathematical Modelling, 9(3-5), 245-250. doi: 10.1016/0270-0255(87)90481-7

Harahap, W., Santoso, I., \& Suryadi, K. (2005, julho). Selection of private participation model in seaport terminal operation case: port of Tanjung Priok Jakarta Indonesia. Proceedings of the International Symposium on the Analytic Hierarchy Process, Honolulu, Hawai, USA.

Keeney, R. L. (1988). Structuring objectives for problems of public interest. Operations Research, 36(3), 396-405. doi: 10.1287/opre.36.3.396

Lane, E. F., \& Verdini, W. A. (1989). A consistency test for AHP decision makers. Decision Scienses, 20(3), 575-590. doi: 10.1111/j.1540-5915.1989.tb01568.x

Lei n. 8.630, de 25 de fevereiro de 1993 (1993). Dispõe sobre o regime jurídico da exploração dos portos organizados e das instalações portuárias e dá outras providências (Lei dos Portos). Brasília, DF. Recuperado de http://www.planalto.gov.br/ccivil_03/leis/18630.htm

Menezes, R. A., Silva, R. B., \& Linhares, A. (2007). Leilões eletrônicos reversos multiatributo: uma abordagem de decisão multicritério aplicada às compras públicas brasileiras. Revista de Administração Contemporânea, 11(3), 11-33. doi: 10.1590/S1415-65552007000300002 
Munda, G., Nijkamp, P., \& Rietveld, P. (1995). Qualitative multicriteria methods for fuzzy evaluation problems: an illustration of economic-ecological evaluation. European Journal of Operational Research, 82(1), 79-97. doi: 10.1016/0377-2217(93)E0250-2

National Oceanic and Atmospheric Administration. (2009). Pacific lease acquisition. Washington, DC: Marine Operations Center.

Queensland Water Commission. (2009). SEQ - Desalination siting study: multicriteria analysis. Australia: Queensland.

Rocha, C. H., Gartner, I. R., \& Cavalcante, L. R. (2011). A model of lease of port areas: a new contribution. Revista de Literatura dos Transportes, 5(3), 4-15.

Roy, B. (1985). Méthodologie multicritère d'aide à la décision. Paris: Economica.

Roy, B. (1990). Decision-aid and decision making. European Journal of Operational Research, 45(23), 324-331. doi: 10.1016/0377-2217(90)90196-I

Roy, B., \& Vincke, P. (1984). Relational systems of preference with one or more pseudo-criteria: some new concepts and results. Management Science, 30(11), 1323-1335. doi: $10.1287 / \mathrm{mnsc} .30 .11 .1323$

Saaty, T. L. (1990). How to make a decision: the analytic hierarchy process. European Journal of Operational Research, 48(1), 9-26. doi: 10.1016/0377-2217(90)90057-I

Saaty, T. L. (1991). Método de análise hierárquica. São Paulo: McGraw-Hill.

Saaty, T. L. (1995). Decision making for leaders: the analytic hierarchy process for decisions in a complex world (3a ed.). Pittsburg, PA: RWS Publications.

Saaty, T. L. (2008). Decision making with the analytic hierarchy process. International Journal of Services Sciences, 1(1), 83-98. doi: 10.1504/IJSSCI.2008.017590

Satir, T., Alkan, G. B., Can, S., \& Bak, O.A. (2007). Port reception facilities: using multi criteria decision making. Turkey: Istambul Technical University.

Saundry, R., \& Turnbull, T. (1997). Private profit, public loss: the financial and economic performance of U. K. ports. Maritime Policy and Management, 24(4), 319-334. doi: $10.1080 / 03088839700000041$

Siskos, Y., \& Spyridakos, A. (1999). Intelligent multicriteria decision support: overview and perspectives. European Journal of Operational Research, 113(2), 236-246. doi: 10.1016/S03772217(98)00213-6

Vargas, L. G. (1990). An overview of the analytic hierarchy process and its applications. European Journal of Operational Research, 48(1), 2-8. doi: 10.1016/0377-2217(90)90056-H Key

World Bank. (2007). Port reform toolkit (Vol. 1-8, 2a ed.). (Public-Private Infrastructure Advisory Facility). Washington: Author. 